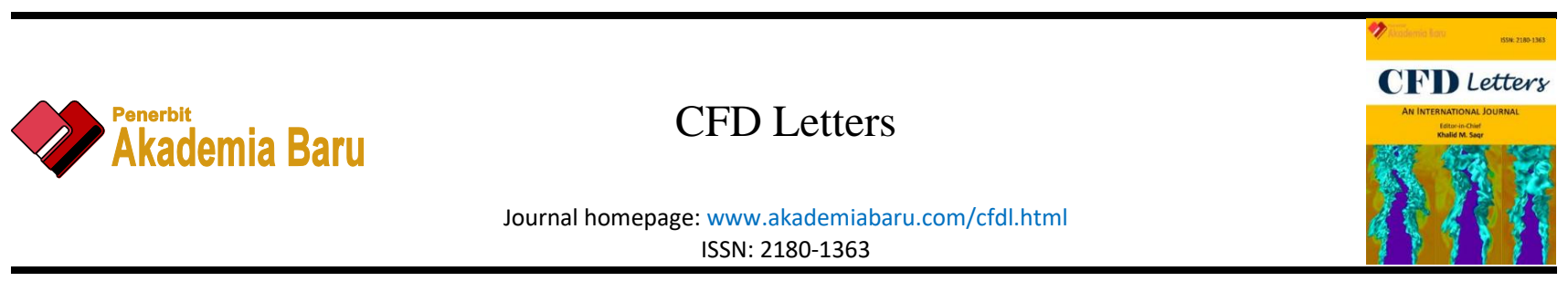

\title{
Flow Topology around Low Reynolds Number Airfoils with Vortex Shedding
}

\author{
Che Intan Hartini Che Ibrahim ${ }^{1}$, Aslam Abdullah ${ }^{1, *}$ \\ Department of Aeronatical Engineering, Faculty of Mechanical and Manufacturing Engineering, Universiti Tun Hussein Onn Malaysia, 86400 \\ Parit Raja, Johor, Malaysia
}

\section{\begin{tabular}{l} 
ARTICLE INFO ABSTRACT \\
\hline
\end{tabular}}

\section{Article history:}

Received 23 October 2020

Received in revised form 24 December 2020

Accepted 21 December 2020

Available online 31 December 2020

Keywords:

Flow topology; vortex shedding; separation bubble; reattachment point

\begin{abstract}
In depth studies on the vortex formation process as well as the periodic behavior of the reattachment profile have been mainly sparked by broad discussions on the flow topology. While the topology methodology is quite well established, the majority of airfoil types have still not been covered. In this study, six low Reynolds number airfoils were considered to investigate the separation bubble structure, vortex shedding and reattachment point. This was done by means of computational fluid dynamics simulations involving the airflow passing several Eppler and Selig models. The method was validated against an established mathematical relationship to indicate that both simulations and analysis technique were reliable. It was observed that the phenomena under investigation directly affect the airfoils aerodynamic performance. In particular, vortex shedding and big reattachment length contribute to the minimum lift. Moreover, high number of vortices in the separation bubble as well as secondary separation bubble result in maximum drag. The results which correspond to low Reynolds number airfoils are applicable in micro aerial vehicles field.
\end{abstract}

\section{Introduction}

Flow topology emphasizes the flow field structure as separation bubble and shedding of vortices [1-4]. These physical phenomena and their complex structures are understood through the topological analysis involving the singular fixed points. The information of bifurcation which is obtained via flow topology can be used to diagnose the critical air loads $[3,5]$. Flow topology is substantial if deeper insights of, for instance, available analysis of flow past airfoils [6,7], and even more specific problems involving the ground effects [8,9], are to be obtained.

The developed oscillating flow induces the vortex shedding which grows and moves before it is able to detach from the surface of the airfoil at the trailing edge. The formation and shedding of the vortices, and the encased bubble between the point of separation and reattachment point on the surface of the airfoil (i.e. separation bubble) significantly affect the aerodynamic performance of

\footnotetext{
* Corresponding author.

E-mail address: aslam@uthm.edu.my (Aslam Abdullah)
} 
airfoils [10]. Failure of the separated flow to reattach to the surface of airfoil will lead to stall condition or loss of lift.

The formation of separation bubble on the surface of airfoil can be longer at low Reynolds number regime, until it reaches complete flow separation leading to stall condition [11]. Hence, the design and geometry of low Reynolds number airfoils can reduce the risk of the complete separation in the application of, for instance, micro aerial vehicle (MAV). The study considered six low Reynolds number airfoils from series of Eppler and Selig (i.e. E387, E374, E392, S3021, S3024, S3025).

Notwithstanding the fact that flow topology has been widely studied among researchers, the majority of airfoil types have yet to be covered. It is important to study the topology in order to gain deeper insights into the separation bubble structure, and vortex shedding as well as reattachment phenomena. This research aims at investigating the effects of these factors on the airfoils' aerodynamic performance for the application in micro aerial vehicle.

\section{Methodology}

The low Reynolds number airfoils' geometry are illustrated in Figure 1 to Figure 6. Respective computational domain, grid and boundary conditions are shown in Figure 7.

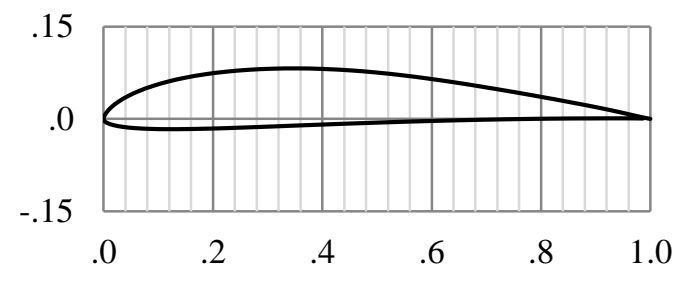

Fig. 1. Airfoil E387

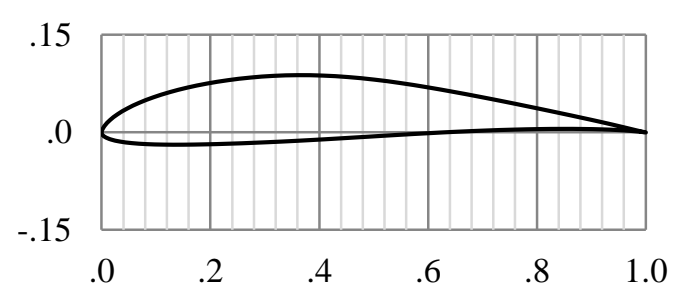

Fig. 3. Airfoil E392

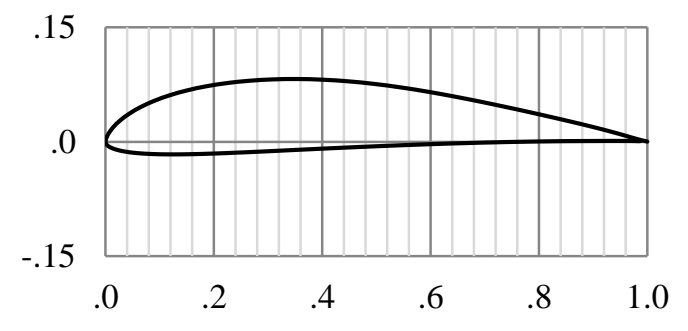

Fig. 5. Airfoil S3024

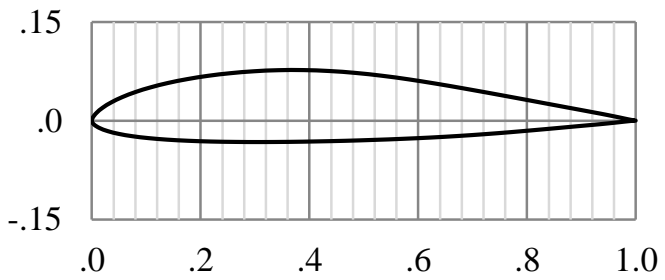

Fig. 2. Airfoil E374

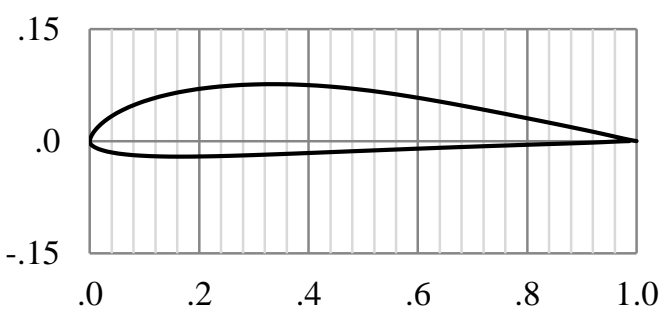

Fig. 4. Airfoil S3021

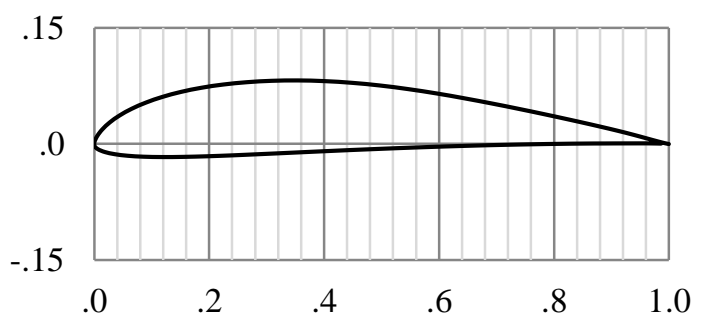

Fig. 6. Airfoil S3025 

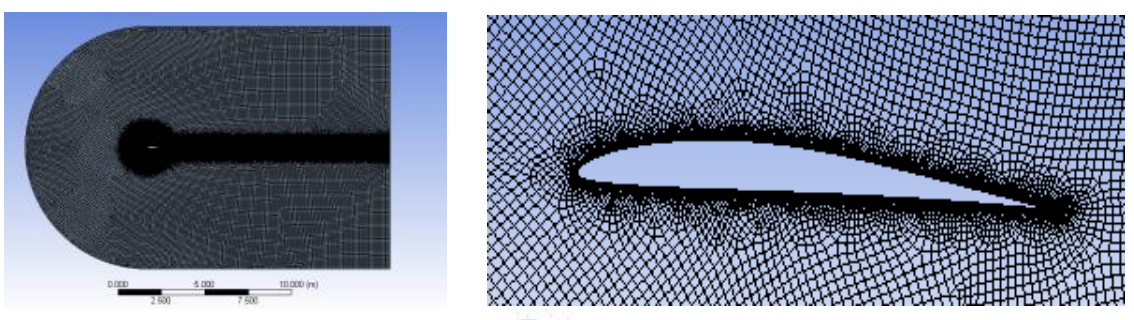

Free

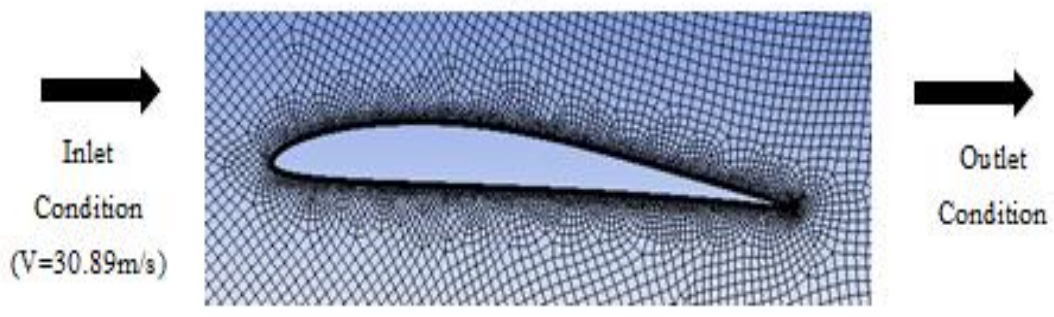

Fig. 7. Grid, domain and boundary conditions

The model of laminar is reliable in observing flow topology with vortex shedding [5,12-15]. Both vortex shedding and separation bubble profile were gained in this study by means of the topological overview of the flow. The transient flow development involved the velocity curl profile over the airfoils in fixed laminar condition. In this simulation, two-dimensional flows over two sets of airfoils (i.e. Eppler and Selig airfoils) were examined and compared. These wing cross sections are applicable for MAVs. The free stream velocity and Reynolds number of interests are $V=30.89 \mathrm{~ms}^{-1}$ and $R e=60000$, respectively. Note that Reynolds number is in the typical range of MAV operation [3], and the chord length of each airfoil was set as 1 meter. The time step for the exported data files was $t=0.012$ time units, although the time step of $t=0.0015$ unit time was used for accuracy and to optimize the appearance of the desired flow structures; in order to conserve memory, only the data at every 8th time step was stored. Since the accurate calculation of Lagrangian coherent structures requires that the grid spacing be small [3], the initial grid spacing of $\Delta x=\Delta y=0.02 \mathrm{~m}$ was employed within the domain $-7 m \leq x \leq 14 m,-7 m \leq y \leq 7 m$ covered by the Cartesian mesh. The simulation considered 600 velocity time steps for $\alpha=4^{\circ}$.

In general 'proximity and curvature' size function, fine relevance center, and maximum face size of $0.1 \mathrm{~m}$ were chosen. Type of body sizing was '(two) body of influence' with element and size growth rate of $0.02 \mathrm{~m}$ and 1.2, respectively, and ' 1 body' geometry selection. 'Edge sizing 1 ' type was 'number of (250) divisions', with sizing behaviour and the geometry were set to be hard and consists of 2 edges, respectively. Edge sizing 2 type was also 'number of (5) divisions', with sizing behaviour was set to be hard for ' 1 edge' geometry. The selected options for inflation technique were ' 1 face' geometry, ' 3 edges' boundary, and inflation of 'total thickness' type with 10 layers, 1.2 growth rate, and $0.01 \mathrm{~m}$ maximum thickness.

The setup included density based solver, absolute velocity formulation, transient condition and planar 2D space, in general. Laminar model was used, while energy equation model was not considered. Constant air density and viscosity values were $1.225 \mathrm{~kg} / \mathrm{m}^{3}$ and $1.7894 \times 10^{-05} \mathrm{~kg} / \mathrm{m} . \mathrm{s}$, respectively. Boundary conditions included no slip wall condition, inlet velocity, 'magnitude and direction' velocity specification method, absolute reference frame, zero initial gauge pressure, and component $x-y=(1,0)$ of flow direction. Outlet type was that of 'pressure-outlet', where absolute backflow reference frame, zero pressure gauge, and 'normal to boundary' backflow direction specification method, were employed. The solution method was that of implicit, with Roe FluxDifference Splitting scheme, spatial discretization of least squares cell based and second order upwind for estimating spatial gradient and flow, respectively. The transient formulation was that of 
second order implicit. In the solution initialization process, standard initialization method which computed from inlet was set, with the reference frame that was relative to cell zone, initial non-zero velocity value only as $x$-component, and initial zero gauge pressure $[3,5,12]$.

Every 8 time steps, the calculation activities were autosaved. Fixed time stepping method was applied, with 600 number of time steps, the maximum of 3700 iterations per reporting interval, and a single profile update interval.

\section{Results}

\subsection{Flow Topology Around E387}

The reverse saddle-node bifurcation as well as vortex shedding occur at $t_{1}$ and $t_{2}$, respectively. The flow topologies of airfoil E387 at three different times are shown in Figure 8 to Figure 10, where the segment imaginary boundaries are represented by the dash lines. The validation of fixed point types and locations have been done against Hunt relationship

$$
\left(\sum E+\frac{1}{2} \sum E^{\prime}\right)-\left(\sum H+\frac{1}{2} \sum H^{\prime}\right)=1-n,
$$

where $E$ is 4-way elliptic point, $E^{\prime}$ is 3-way elliptic point, $H$ is 4-way hyperbolic point, $H^{\prime}$ is 3 -way hyperbolic point, and $n$ is connectivity. The corresponding values are shown in Table 1.

Table 1

Validation of topological fixed points in the flow over Eppler E387 where Eq. (1) is satisfied when $n=2$

\begin{tabular}{lllll}
\hline Time & $\mathrm{E}$ & $\mathrm{E}^{\prime}$ & $\mathrm{H}$ & $\mathrm{H}^{\prime}$ \\
\hline $\mathrm{t}_{1}$ & 12 & 0 & 9 & 8 \\
$\mathrm{t}_{2}$ & 11 & 0 & 7 & 10 \\
$\mathrm{t}_{3}$ & 10 & 0 & 6 & 10 \\
\hline
\end{tabular}

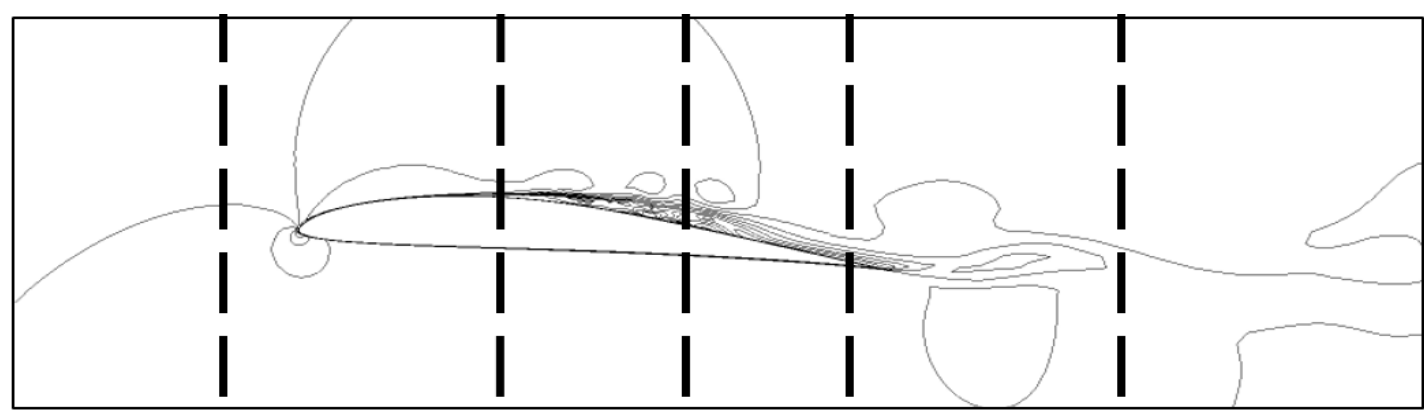

Fig. 8. Flow topology around $\mathrm{E} 387$ with $R e=60,000$ at $\alpha=4^{\circ}$ at $t_{1}$

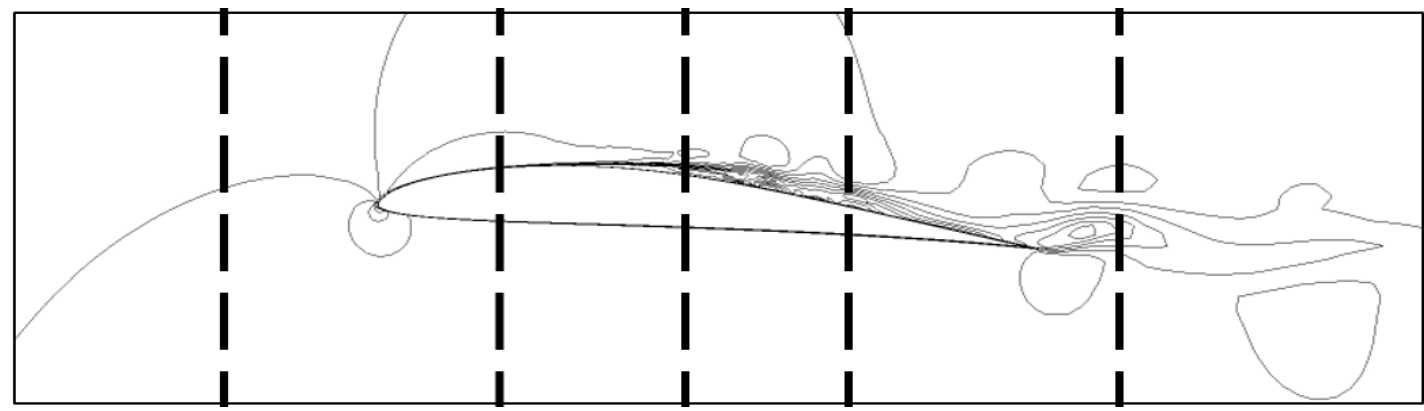

Fig. 9. Flow topology around $\mathrm{E} 387$ with $\operatorname{Re}=60,000$ at $\alpha=4^{\circ}$ at time $t_{2}$ 


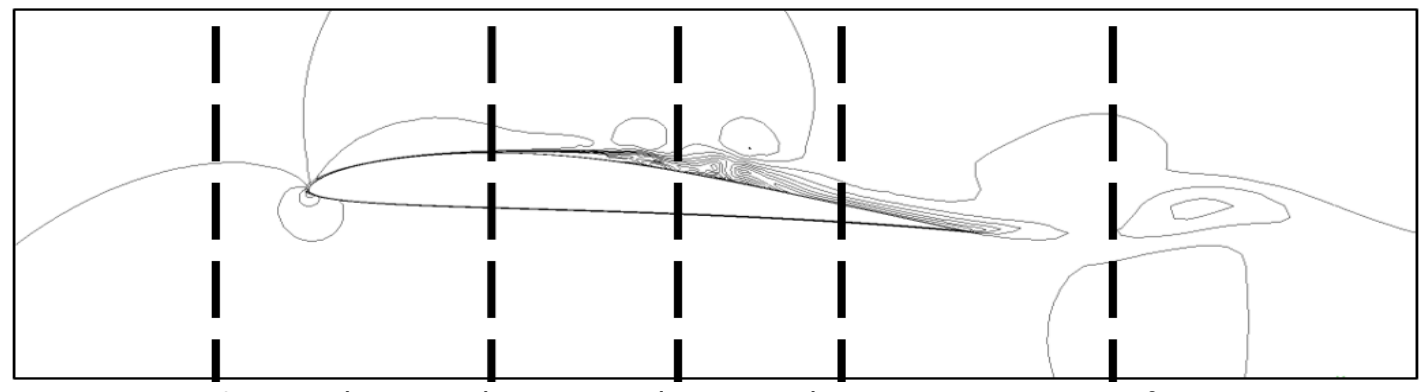

Fig. 10. Flow topology around E387 with $R e=60,000$ at $\alpha=4^{\circ}$ at $t_{3}$

In segment 2 as shown in Figure 11, the occurrence of separation bubble is observed. At $t_{1}$, the hyperbolic fixed points, $\mathrm{H} 1$ and $\mathrm{H} 2$ collide each other to form new hyperbolic fixed point just below an elliptic fixed point, E1. Consequently, the new point collides with E1. The collision between these two fixed points is called reverse-saddle node bifurcation which causes the collided points to cancel out each other, and enables new vortex to separate from the separation bubble towards the trailing edge of the airfoil.

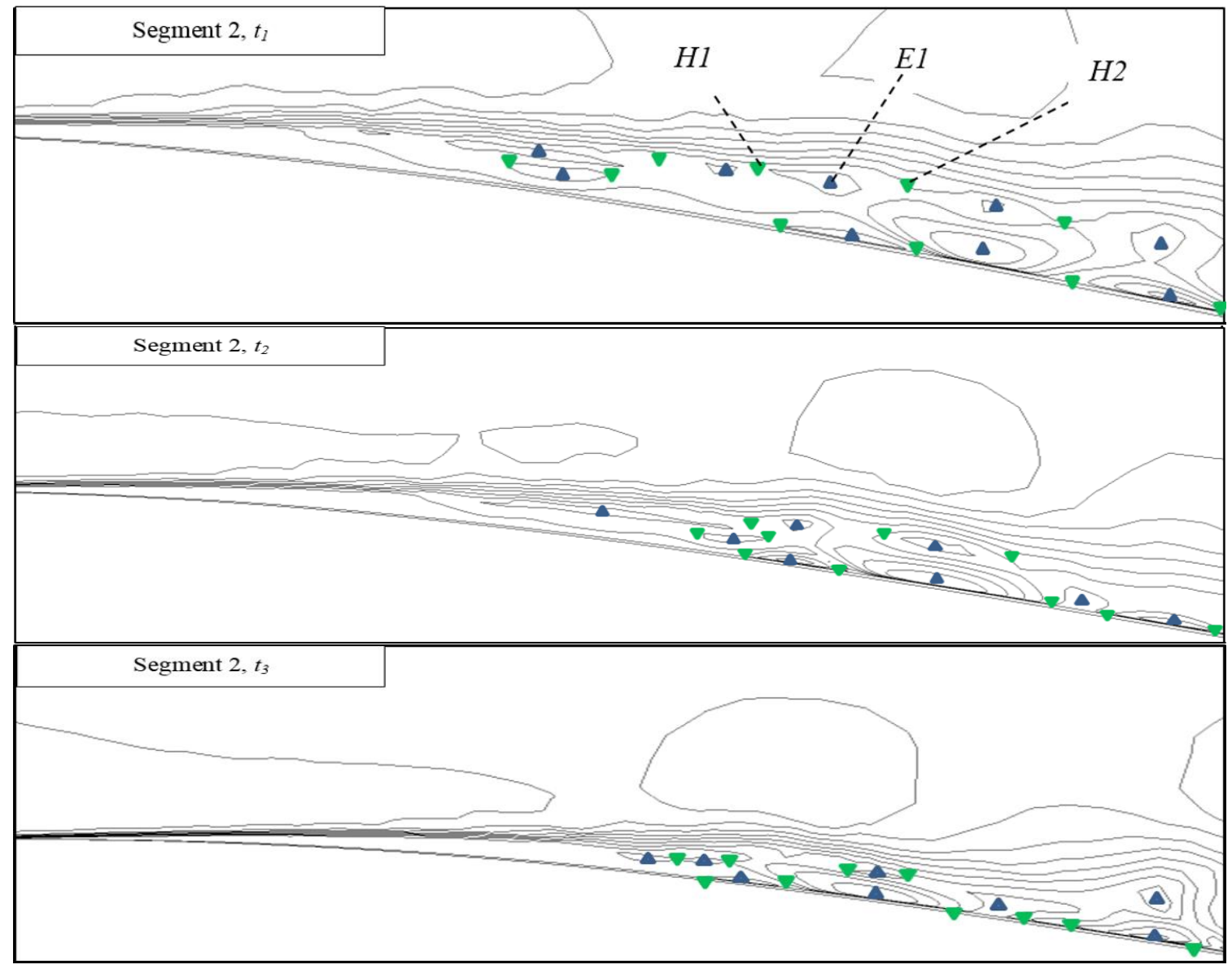

Fig. 11. Segmented flow topology (segment 2) around E387 with $R e=60,000$ at $\alpha=4^{\circ}$

At $t_{2}$ in segment 2 , the separation bubble becomes smaller, resulting from the occurrence of reverse-saddle node bifurcation that separates a new vortex from the bubble.

Observation on segment 3 shown in Figure 12 indicates that there is no occurrence involving the issue of interest at three different times. Although changes in flow topology pattern are observable, no further process is seen. The hyperbolic fixed point labeled as $\mathrm{H} 3$ at $t_{2}$ will be further discussed in segment 4. 


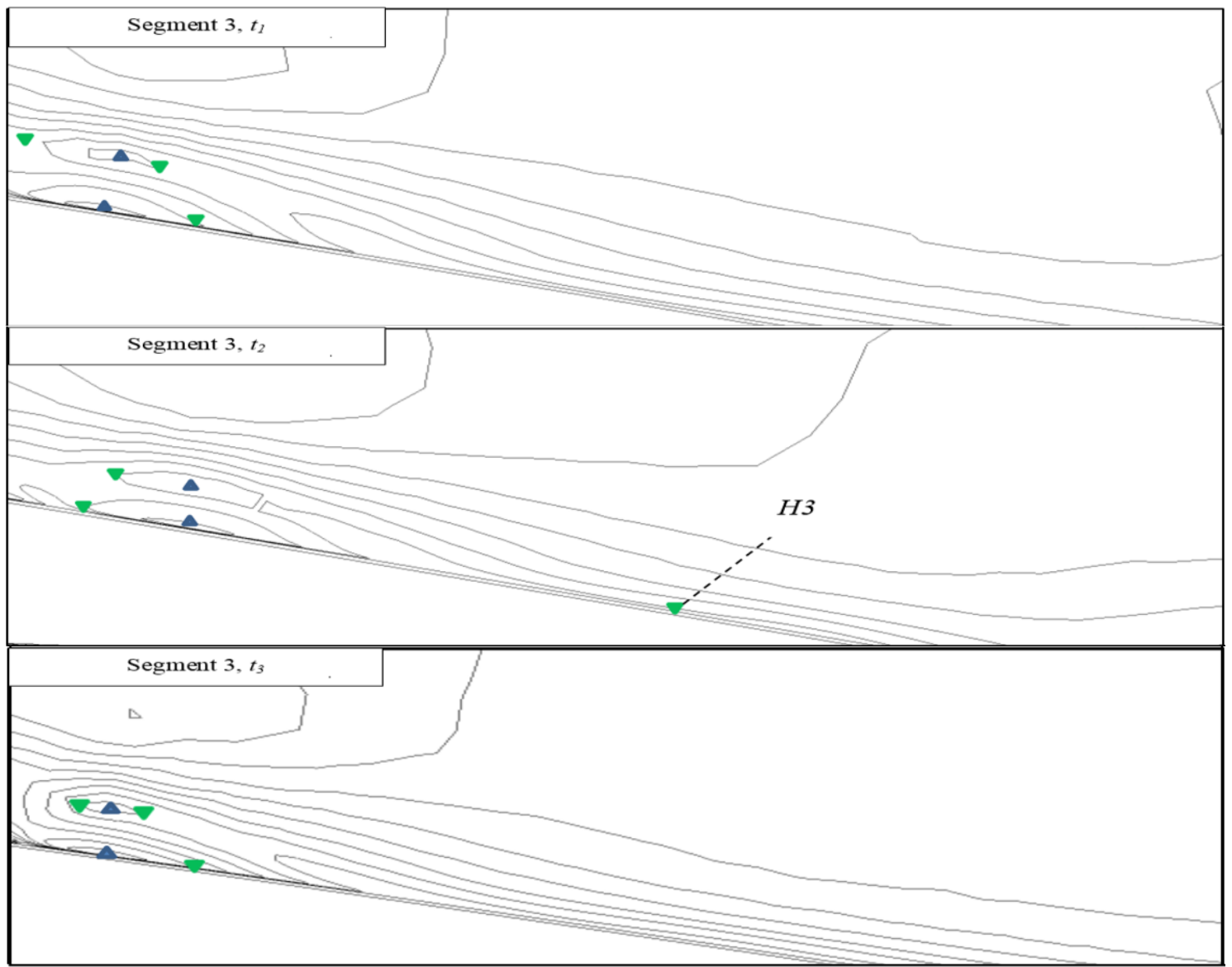

Fig. 12. Segmented flow topology (segment 3) around E387 with $R e=60,000$ at $\alpha=4^{\circ}$

A hyperbolic fixed point, $\mathrm{H} 4$ in segment 4 shown in Figure 13 collides with another point, $\mathrm{H} 3$ from segment 3 . The collision causes the corresponding vortex to be completely separated from the surface of the airfoil which can be observed at $t_{3}$. This initiates the occurrence of vortex shedding. The resulting newly formed hyperbolic fixed point is located just below the shed vortices.

The downstream of the airfoil is within segment 5 in which the shed vortices appear. Note, however, that any occurrence in this segment is beyond the scope of this work.

Flow topology at $t_{1}$ shows the thinner separation bubble which makes the air flow smoother on the surface of the airfoil. At $t_{1}$ also, reverse saddle-node bifurcation occurs as a result of the collision of E1 with the newly formed hyperbolic fixed point due to the collision between $\mathrm{H} 1$ and $\mathrm{H} 2$. The occurrence of vortex shedding is not observed at the trailing edge of the airfoil. Hence, the airfoil does not experience the effects of vortex shedding at this stage/time. From these multiple occurrences, the value of lift coefficient at $t_{1}$ is the highest among those at three different times as shown in Table 2.

At $t_{2}$, the vortex at the trailing edge of the airfoil is by now ready to shed. The shedding would take place once $\mathrm{H} 3$ and $\mathrm{H} 4$ collide which causes the formation of a new hyperbolic fixed point below the shed vortex. Due to the occurrence of vortex shedding, the value of lift coefficient was the lowest at $t_{2}$.

At $t_{3}$ which is the time just after the vortex is completely shed and detached from the surface, the lift coefficient is slightly higher than that at $t_{2}$. 


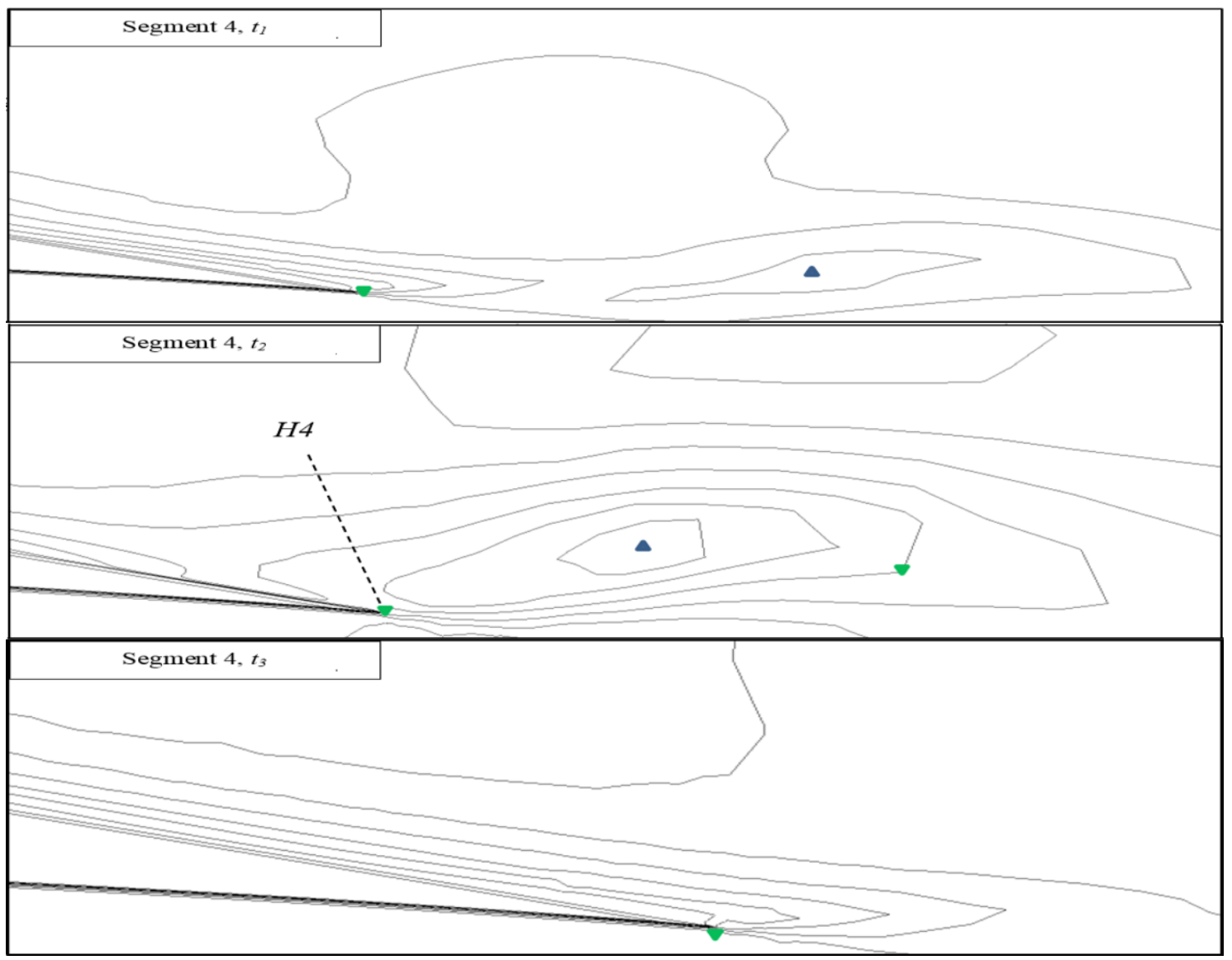

Fig. 13. Segmented flow topology (segment 4) around E387 with $R e=60,000$ at $\alpha=4^{\circ}$

Table 2

Values of $c_{l}$ and $c_{d}$

\begin{tabular}{lll}
\hline Time & $\mathrm{c}_{1}$ & $\mathrm{c}_{\mathrm{d}}$ \\
\hline $\mathrm{t}_{1}$ & $8.0847 \times 10^{-1}$ & $2.9893 \times 10^{-2}$ \\
$\mathrm{t}_{2}$ & $7.1044 \times 10^{-1}$ & $1.5254 \times 10^{-2}$ \\
$\mathrm{t}_{3}$ & $7.8078 \times 10^{-1}$ & $2.2039 \times 10^{-2}$ \\
\hline
\end{tabular}

\subsection{Flow Topology Around E374}

The reverse saddle-node bifurcation occurs in E374 case at $t_{1}$ while shedding of vortex occurs twice at $t_{2}$ and $t_{3}$. The agreement between the topology and the corresponding Hunt relationship in Eq. (1) is given in Table 3.

\section{Table 3}

Validation of topological fixed points in the flow over Eppler E374 where Eq. (1) is satisfied when $n=3$

\begin{tabular}{lllll}
\hline Time & $\mathrm{E}$ & $\mathrm{E}^{\prime}$ & $\mathrm{H}$ & $\mathrm{H}^{\prime}$ \\
\hline $\mathrm{t}_{1}$ & 5 & 0 & 4 & 6 \\
$\mathrm{t}_{2}$ & 10 & 0 & 7 & 10 \\
$\mathrm{t}_{3}$ & 8 & 0 & 5 & 10 \\
\hline
\end{tabular}

In segment 1, there is no occurrence at the three different times, while in segment 2 shown in Figure 14, reverse saddle node bifurcation occurs at $t_{1}$ which involves the collision between an elliptic fixed point, E1 and a hyperbolic fixed point, $\mathrm{H} 1$. The collision splits the existing vortex into two vortices on the surface of the airfoil. 


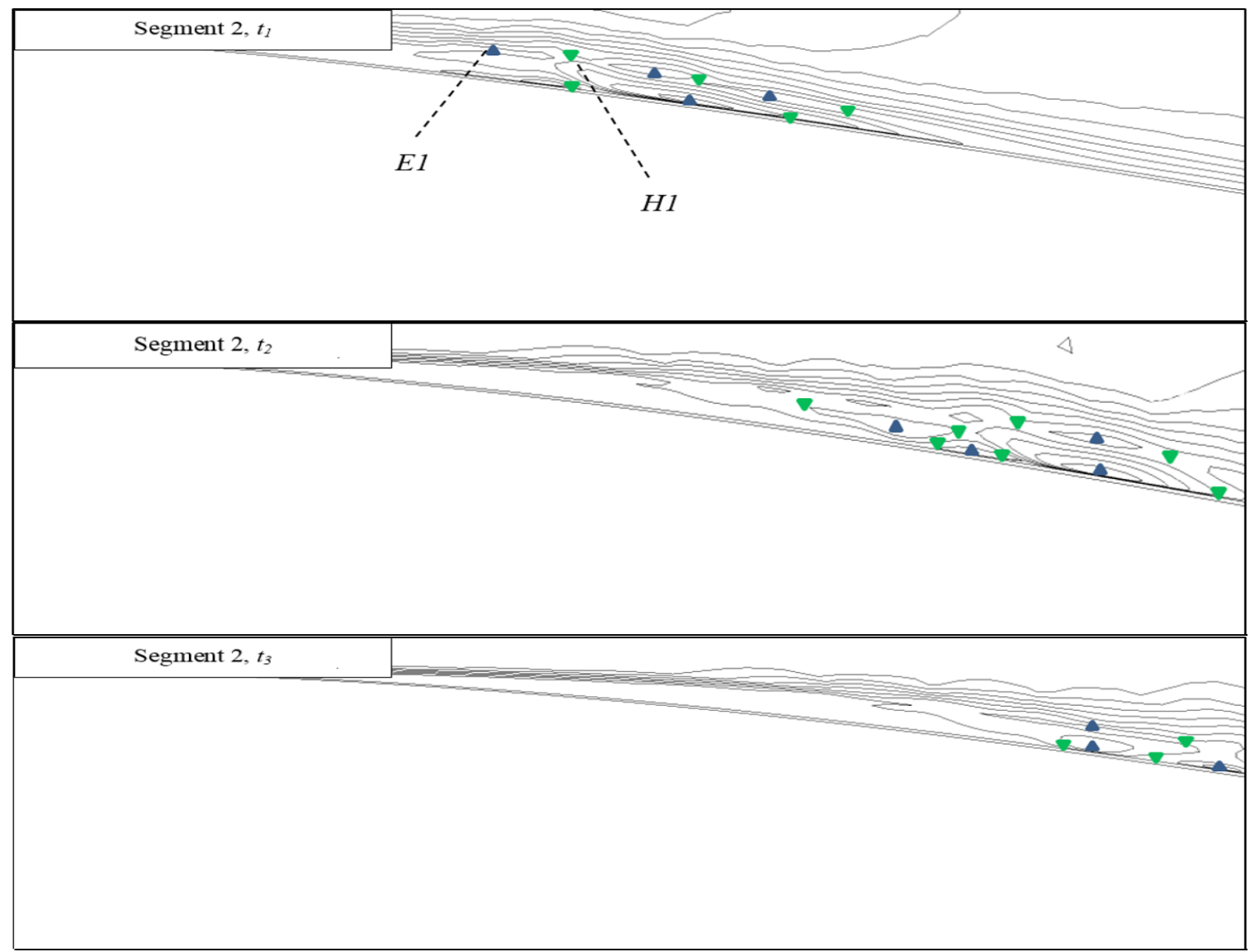

Fig. 14. Segmented flow topology (Segment 2) around E374 with $R e=60,000$ at $\alpha=4^{\circ}$

In segment 3, there is no occurrence of interest. However, the transition and the movement of vortices can be seen.

The event of vortex shedding can be observed twice in segment 4 shown in Figure 15 which is at $t_{2}$ and $t_{3}$ due to the collisions of $\mathrm{H} 3-\mathrm{H} 4$, and $\mathrm{H} 5-\mathrm{H} 6$, respectively. Segment 5 corresponds to the downstream of the airfoil in which the shed vortices appear.

As given in Table 4, the highest lift coefficient of $5.6640 \times 10^{-1}$ is observed at $t_{1}$, while the lowest coefficient of $4.4867 \times 10^{-1}$ is found at $t_{3}$.

From the topological overview, the thickness of the separation bubble affects the drag. At $t_{3}$, the drag is the lowest since the bubble is at its minimum thickness. However, the lift decreases at the same time (i.e. at $t_{3}$ ) due to the presence of vortex shedding.

Table 4

Values of $c_{l}$ and $c_{d}$

\begin{tabular}{lll}
\hline Time & $\mathrm{Cl}_{\mathrm{l}}$ & $\mathrm{C}_{\mathrm{d}}$ \\
\hline $\mathrm{t}_{1}$ & $5.6640 \times 10^{-1}$ & $1.8709 \times 10^{-2}$ \\
$\mathrm{t}_{2}$ & $5.0579 \times 10^{-1}$ & $1.2383 \times 10^{-2}$ \\
$\mathrm{t}_{3}$ & $4.4867 \times 10^{-1}$ & $4.8104 \times 10^{-3}$ \\
\hline
\end{tabular}




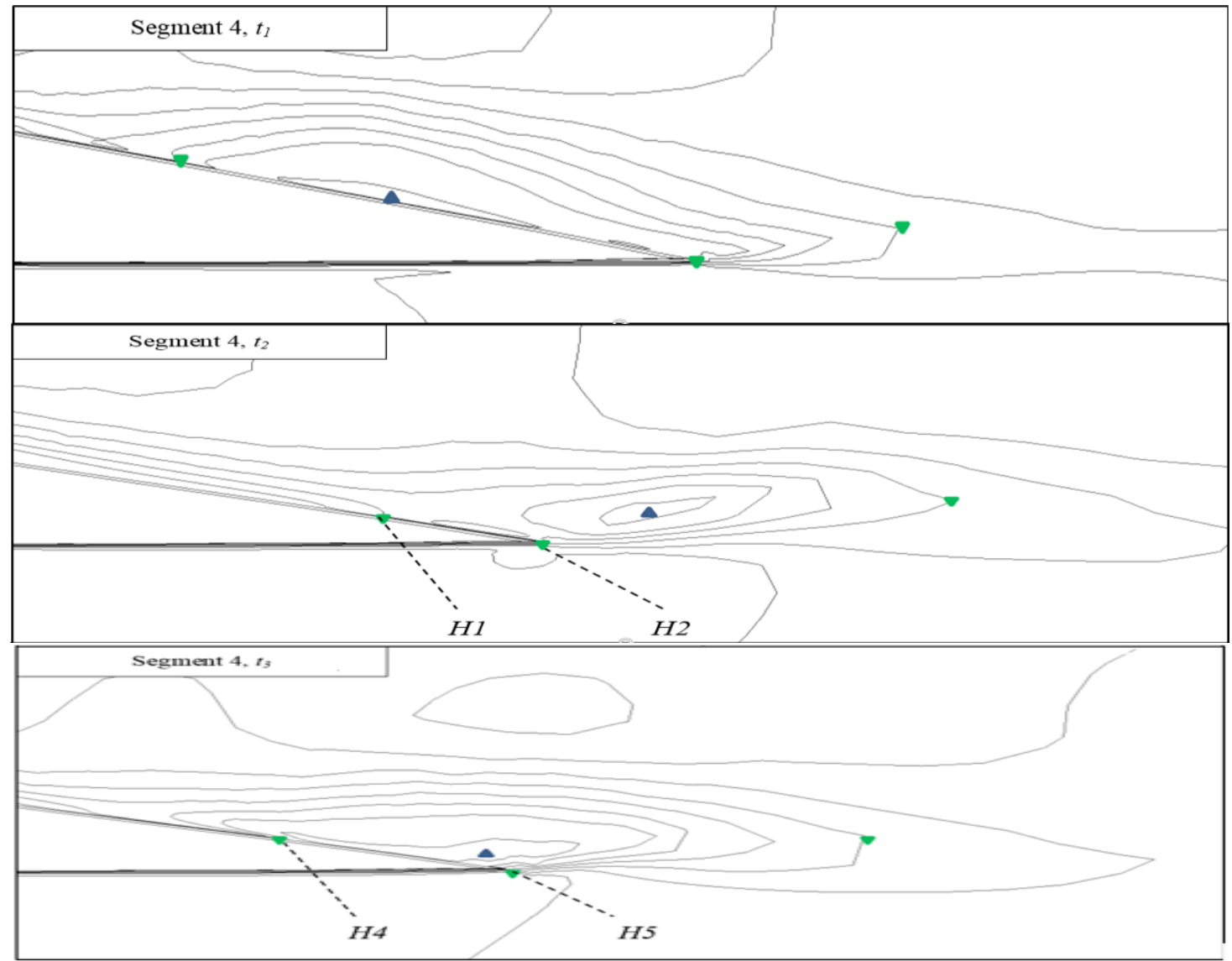

Fig. 15. Segmented flow topology (segment 4) around E374 with $R e=60,000$ at $\alpha=4^{\circ}$

\subsection{Flow Topology Around E392}

At $t_{1}$ in E392 case, the reverse saddle-node bifurcation takes place, while at $t_{3}$ the vortex is shed. In Table 5, the topology-Hunt relationship agreement is shown.

\section{Table 5}

Validation of topological fixed points in the flow over E392 where Eq. (1) is satisfied when $n=2$

\begin{tabular}{lllll}
\hline Time & $\mathrm{E}$ & $\mathrm{E}^{\prime}$ & $\mathrm{H}$ & $\mathrm{H}^{\prime}$ \\
\hline $\mathrm{t}_{1}$ & 12 & 0 & 8 & 10 \\
$\mathrm{t}_{2}$ & 11 & 0 & 7 & 10 \\
$\mathrm{t}_{3}$ & 11 & 0 & 9 & 6 \\
\hline
\end{tabular}

There is no interesting event in segment 1 . However, reverse saddle node bifurcation takes place in segment 2 at $t_{1}$ after an elliptic fixed point, E1 collides with a newly formed hyperbolic fixed point (i.e. that results from the collision of $\mathrm{H} 1$ and $\mathrm{H} 2$ ). The collision separates a newly formed vortex from the existing one. The segmented flow topology in segment 2 is illustrated in Figure 16. 


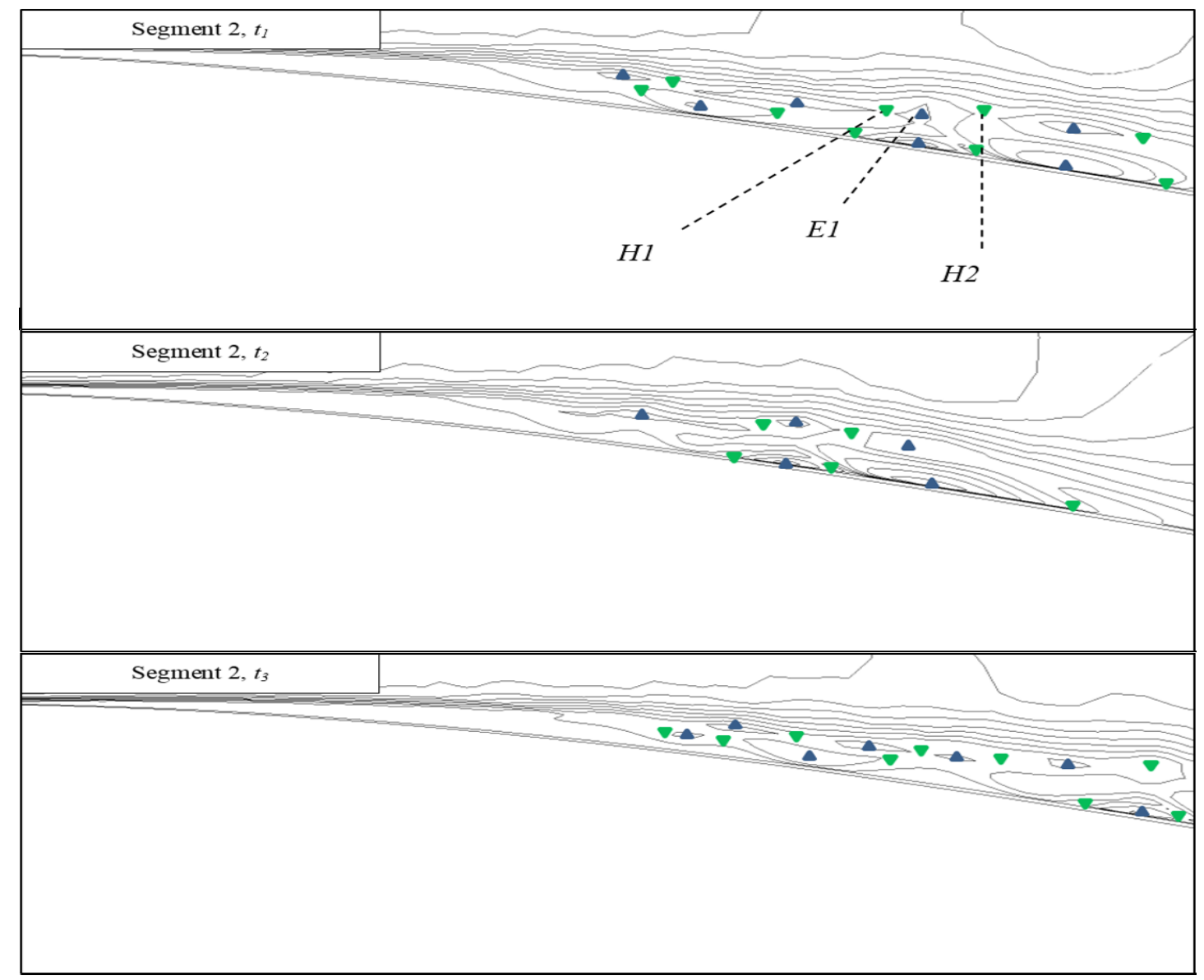

Fig. 16. Segmented flow topology (Segment 2) around E392 with $R e=60,000$ at $\alpha=4^{\circ}$

Despite changes in flow topology pattern in segment 3, the segment shows no significant event. The hyperbolic fixed point $\mathrm{H} 3$ in segment 3 , as shown in Figure 17, would involve in the collision with another hyperbolic point in segment $4, \mathrm{H} 4$ at $t_{3}$ as shown in Figure 18. This collision initiates the vortex shedding.

Segment 5 highlights the area behind the airfoil and normally portrays the shed vortex that has been detached from the surface of the airfoil. However, the study does not include the analysis of the area behind the airfoil.

The highest lift is obtained at $t_{2}$ where the lift coefficient takes the value of $6.9714 \times 10^{-1}$. At $t_{1}$, the coefficient takes the smallest value of $6.6406 \times 10^{-1}$. Complete lift and drag coefficients at three respective time are recorded in Table 6.

The lift at $t_{2}$ is high in comparison to that at $t_{1}$ due to the relatively shorter reattachment length (see segment 2 ), while the presence of a secondary separation bubble at $t_{2}$ in segment 3 contributes to high drag.

Thinner vortices can be seen at $t_{3}$ which is caused by the reverse saddle-node bifurcation. Thus, the drag is lower at this time. The lift at $t_{3}$, however, decreases as a result of vortex shedding.

Table 6

Values of $c_{l}$ and $c_{d}$

\begin{tabular}{lll}
\hline Time & $\mathrm{Cl}_{1}$ & $\mathrm{Cd}$ \\
\hline $\mathrm{t}_{1}$ & $6.6406 \times 10^{-1}$ & $2.7324 \times 10^{-3}$ \\
$\mathrm{t}_{2}$ & $6.9714 \times 10^{-1}$ & $8.1822 \times 10^{-3}$ \\
$\mathrm{t}_{3}$ & $6.7221 \times 10^{-1}$ & $5.3508 \times 10^{-3}$ \\
\hline
\end{tabular}




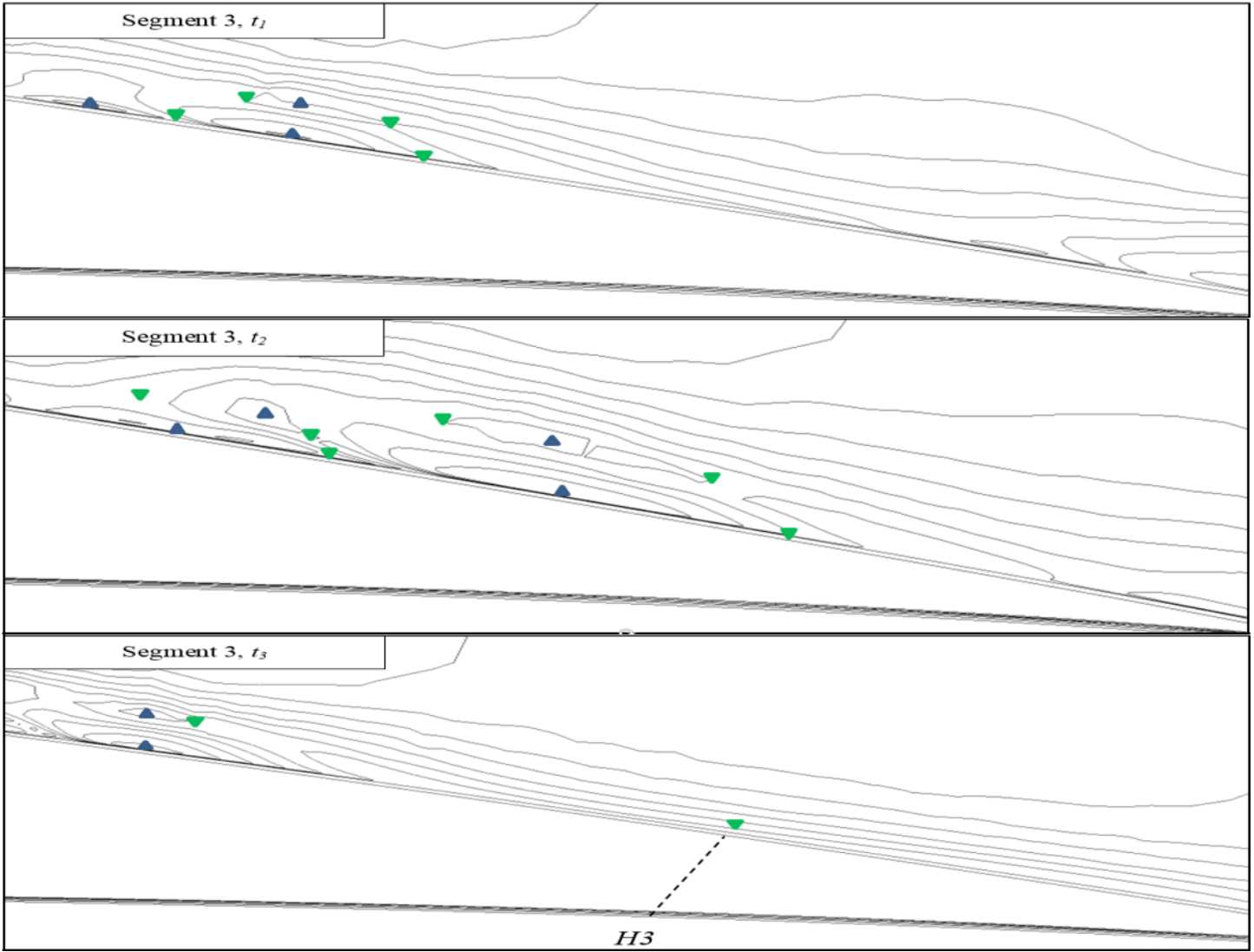

Fig. 17. Segmented flow topology (segment 3) around $\mathrm{E} 392$ with $R e=60,000$ at $\alpha=4^{\circ}$

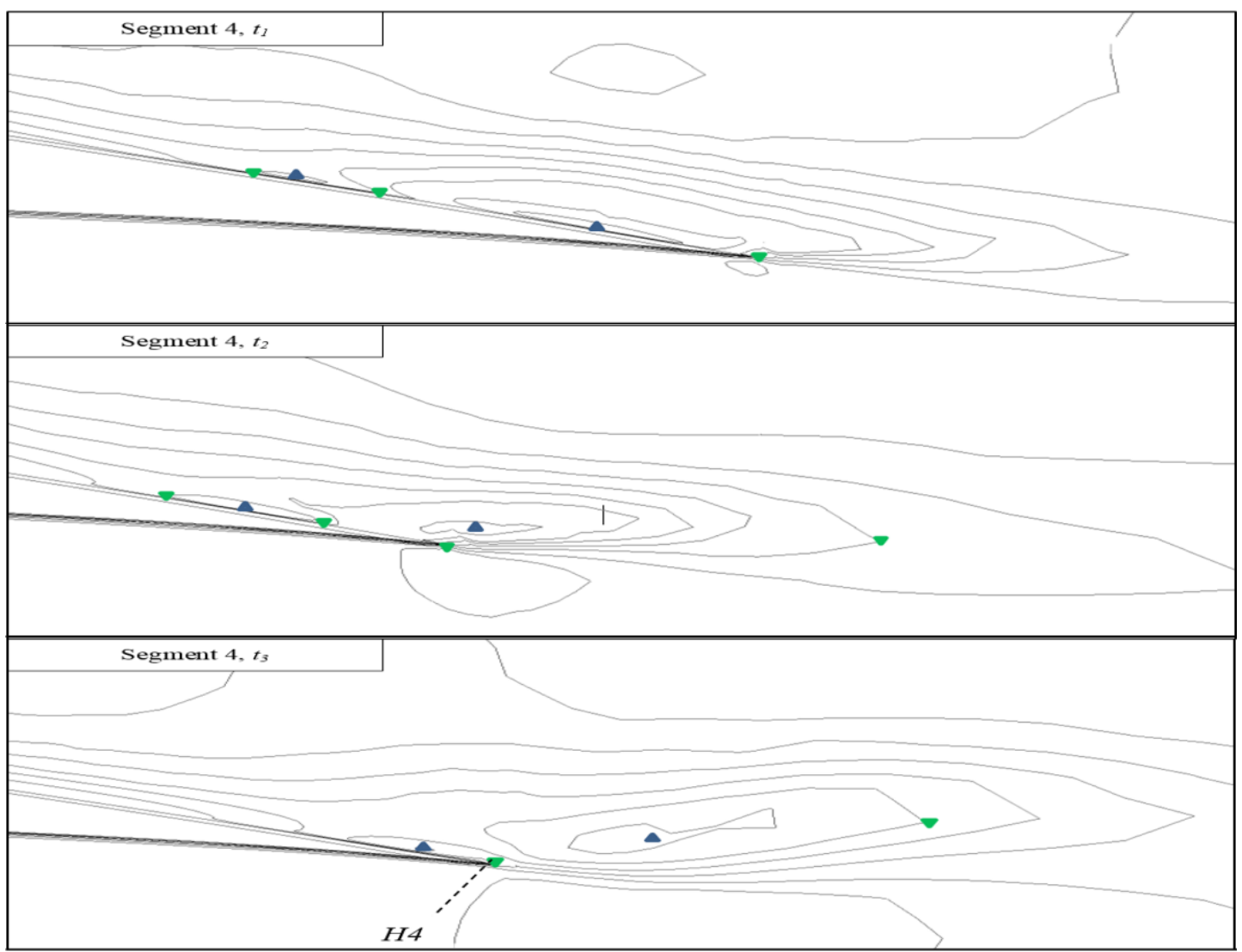

Fig. 18. Segmented flow topology (segment 4) around E392 with $\operatorname{Re}=60,000$ at $\alpha=4^{\circ}$ 


\subsection{Flow Topology Around Airfoil S3024}

It is found that, in the case of $\mathrm{S} 3024$, the reverse saddle-node bifurcation as well as shedding of vortex take place at $t_{2}$ and $t_{3}$, respectively. All types of fixed point at $t_{1}, t_{2}$, and $t_{3}$ are validated against Eq. (1) as shown in Table 7.

Table 7

Validation of topological fixed points in the flow over S3024 where Eq. (1) is satisfied when $n=2$

\begin{tabular}{lllll}
\hline Time & $\mathrm{E}$ & $\mathrm{E}^{\prime}$ & $\mathrm{H}$ & $\mathrm{H}^{\prime}$ \\
\hline $\mathrm{t}_{1}$ & 8 & 0 & 5 & 8 \\
$\mathrm{t}_{2}$ & 8 & 0 & 5 & 8 \\
$\mathrm{t}_{3}$ & 9 & 0 & 5 & 10 \\
\hline
\end{tabular}

Segment 1 captures no significant event at each time of interest. It can be seen at $t_{1}$ to $t_{2}$ of the flow topology in segment 2, shown in Figure 19, that an elliptic fixed point, E1, and those of hyperbolic, $\mathrm{H} 1$ and $\mathrm{H} 2$, move toward the rear of the separation bubble. The movement causes the collision between $\mathrm{E} 1$ and a newly formed hyperbolic fixed point resulting from the collision of $\mathrm{H} 1$ and $\mathrm{H} 2$. The collision between the elliptic and the hyperbolic fixed points lead to occurrence of reverse saddle-node bifurcation, where they destroy each other and separate a new vortex from the separation bubble.

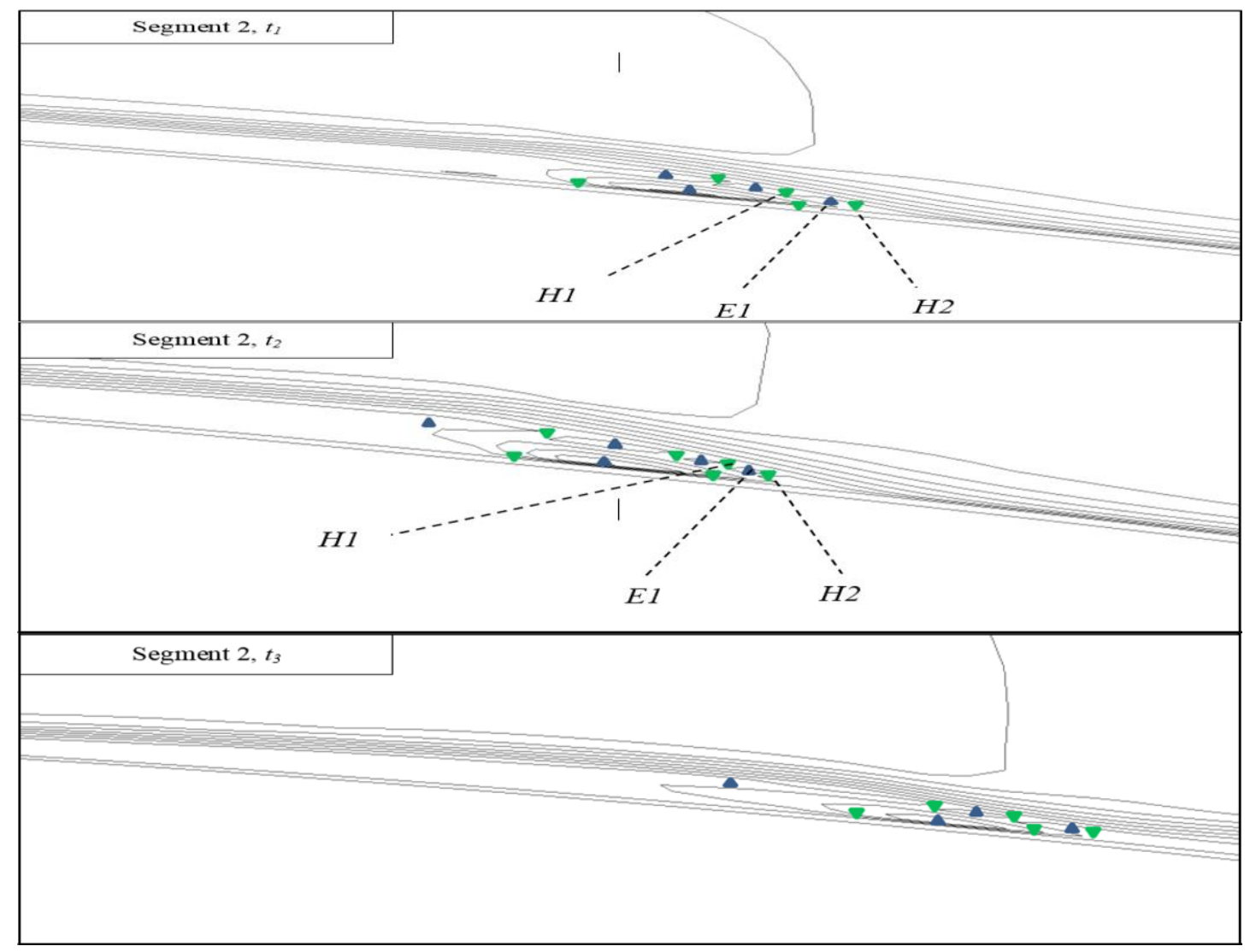

Fig. 19. Segmented flow topology (segment 2) around S3024 with $R e=60,000$ at $\alpha=4^{\circ}$

Segment 3 shown reveals the movement and the change of the topological fixed points before the vortex is ready to be shed in segment 4 that is shown in Figure 20. At $t_{2}$ and $t_{3}$ in segment 4 , threeway hyperbolic points collide with each other; $\mathrm{H} 3$ and $\mathrm{H} 5$ collide with $\mathrm{H} 4$ and $\mathrm{H} 6$, respectively, as they move towards the rear of the airfoil until they get separated from the airfoil surface. For this airfoil, 
the occurrence of vortex shedding cannot be directly observed at the selected times (i.e. at $t_{1}, t_{2}$, and $\left.t_{3}\right)$. However, the prediction can be made as the vortices are nearly shed at the trailing edge and by observing the movement of the fixed points. Segment 5 focuses on the downstream of the airfoil which is beyond the scope of the study.

As shown in Table 8, the highest lift is obtained at $t_{3}$ where its coefficient $c_{l}=7.9787 \times 10^{-1}$, while the lowest lift coefficient is found at $t_{2}$ where $c_{l}=7.4386 \times 10^{-1}$. The lift is the highest at $t_{3}$ due relatively thinner separation bubble on the airfoil surface. Moreover, the vortex shedding negatively affects the lift of the airfoil at $t_{2}$. However, the drag is the lowest at $t_{2}$. The reason is at $t_{2}$, there are least vortices in the separation bubble on the surface of the airfoil.

Table 8

\begin{tabular}{lll}
\multicolumn{3}{c}{ Values of $c_{l}$ and $c_{d}$} \\
\hline Time & $c_{1}$ & $c_{d}$ \\
\hline $\mathrm{t}_{1}$ & $7.7862 \times 10^{-1}$ & $8.0568 \times 10^{-3}$ \\
$\mathrm{t}_{2}$ & $7.4386 \times 10^{-1}$ & $1.2058 \times 10^{-3}$ \\
$\mathrm{t}_{3}$ & $7.9787 \times 10^{-1}$ & $7.3116 \times 10^{-3}$ \\
\hline
\end{tabular}

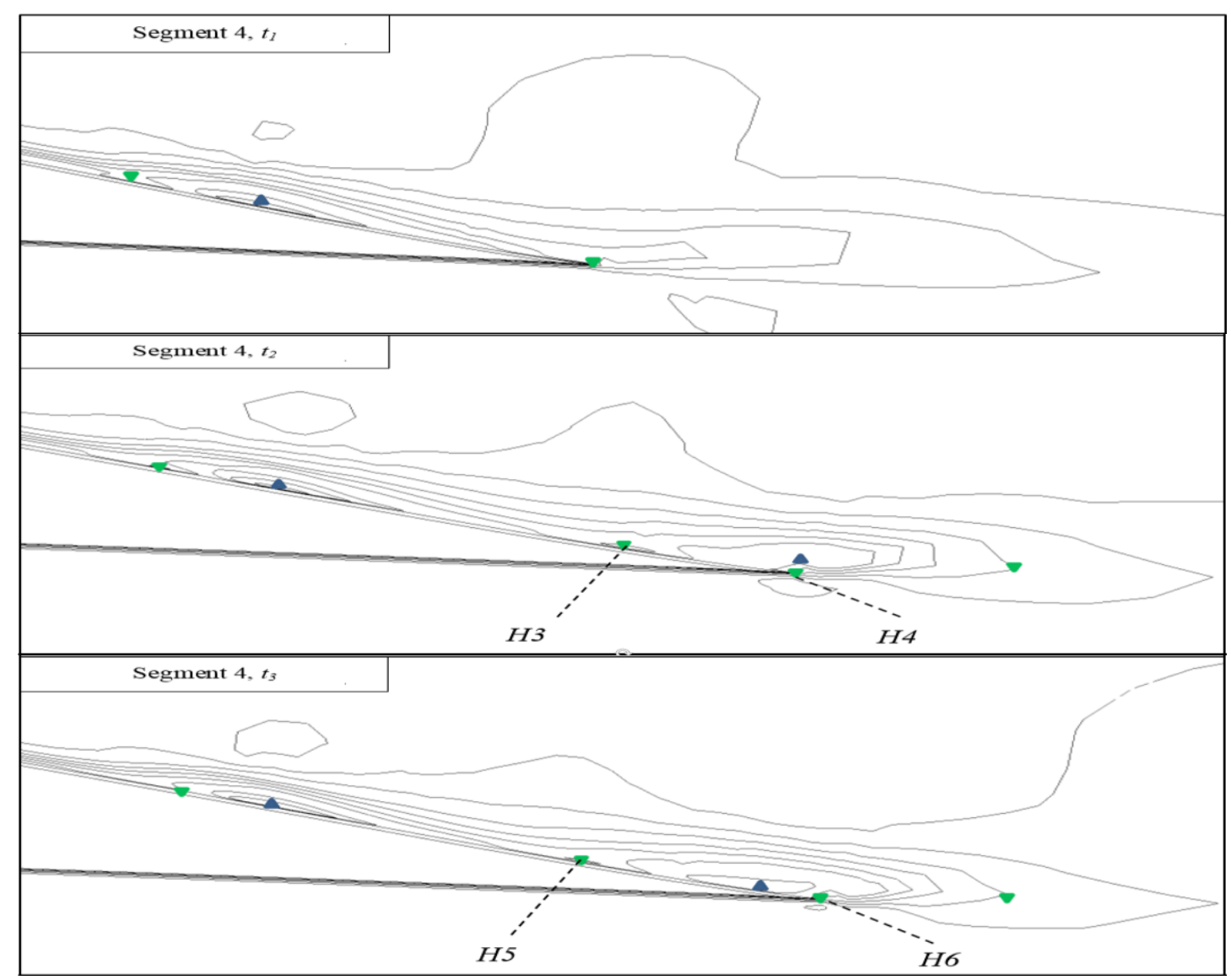

Fig. 20. Segmented flow topology (segment 4) around S3024 with $R e=60,000$ at $\alpha=4^{\circ}$

\subsection{Flow Topology Around Airfoil S3025}

In the case S3025, the reverse saddle-node bifurcation occurs at $t_{2}$ while shedding of vortex occurs at $t_{3}$. The number of each type of fixed points at three different time as shown in Table 9 is confirmed by Eq. (1). 
As in the previous case (i.e. that of S3024), segment 1 reveals no occurrence at every time of interest. Based on the flow topology at $t_{1}$ to $t_{2}$ in segment 2 shown in Figure 21, an elliptic fixed point, $\mathrm{E} 1$, and those of hyperbolic, $\mathrm{H} 1$ and $\mathrm{H} 2$, move towards the rear of the separation bubble, causing the collision between $\mathrm{E} 1$ and a newly formed hyperbolic fixed point (i.e. that resulting from collision of $\mathrm{H} 1$ and $\mathrm{H} 2$ ). The collision between these fixed points leads to reverse saddle-node bifurcation, the situation in which the points eliminate each other and split the separation bubble to form a new vortex. Note that $\mathrm{H} 1, \mathrm{H} 2$ and $\mathrm{E} 1$ can be observed as earlier as at $t_{1}$.

Table 9

Validation of topological fixed points in the flow over S3025 where Eq. (1) is satisfied when $n=2$

\begin{tabular}{lllll}
\hline Time & $\mathrm{E}$ & $\mathrm{E}^{\prime}$ & $\mathrm{H}$ & $\mathrm{H}^{\prime}$ \\
\hline $\mathrm{t}_{1}$ & 7 & 0 & 4 & 8 \\
$\mathrm{t}_{2}$ & 5 & 0 & 1 & 10 \\
$\mathrm{t}_{3}$ & 8 & 0 & 5 & 8 \\
\hline
\end{tabular}

The separation bubble's movement is captured in segment 3. In segment 4 shown in Figure 22, at $t_{3}$, two three-way hyperbolic points, namely $\mathrm{H} 3$ and $\mathrm{H} 4$ collide as they move towards the rear of the airfoil and finally completely detach from its surface. This creates a new four-way hyperbolic point just below the shed vortex.

Referring to Table 10, at $t_{2}$, the lift coefficient $c_{l}=8.3160 \times 10^{-1}$ which is the largest while at $t_{3}$, $c_{l}=7.5115 \times 10^{-1}$ which is the smallest. At $t_{2}$, the separation bubble is the thinnest in comparison to that at $t_{1}$ and $t_{3}$. At $t_{3}$, the number of vortices in the separation bubble is maximum which indirectly increase its thickness, and the vortex is shed, which in turn degrade the lift significantly. Note that the vortex shedding also occurs at $t_{1}$. Clearly, the addition of vortices in the separation bubble would negatively affect the lift.

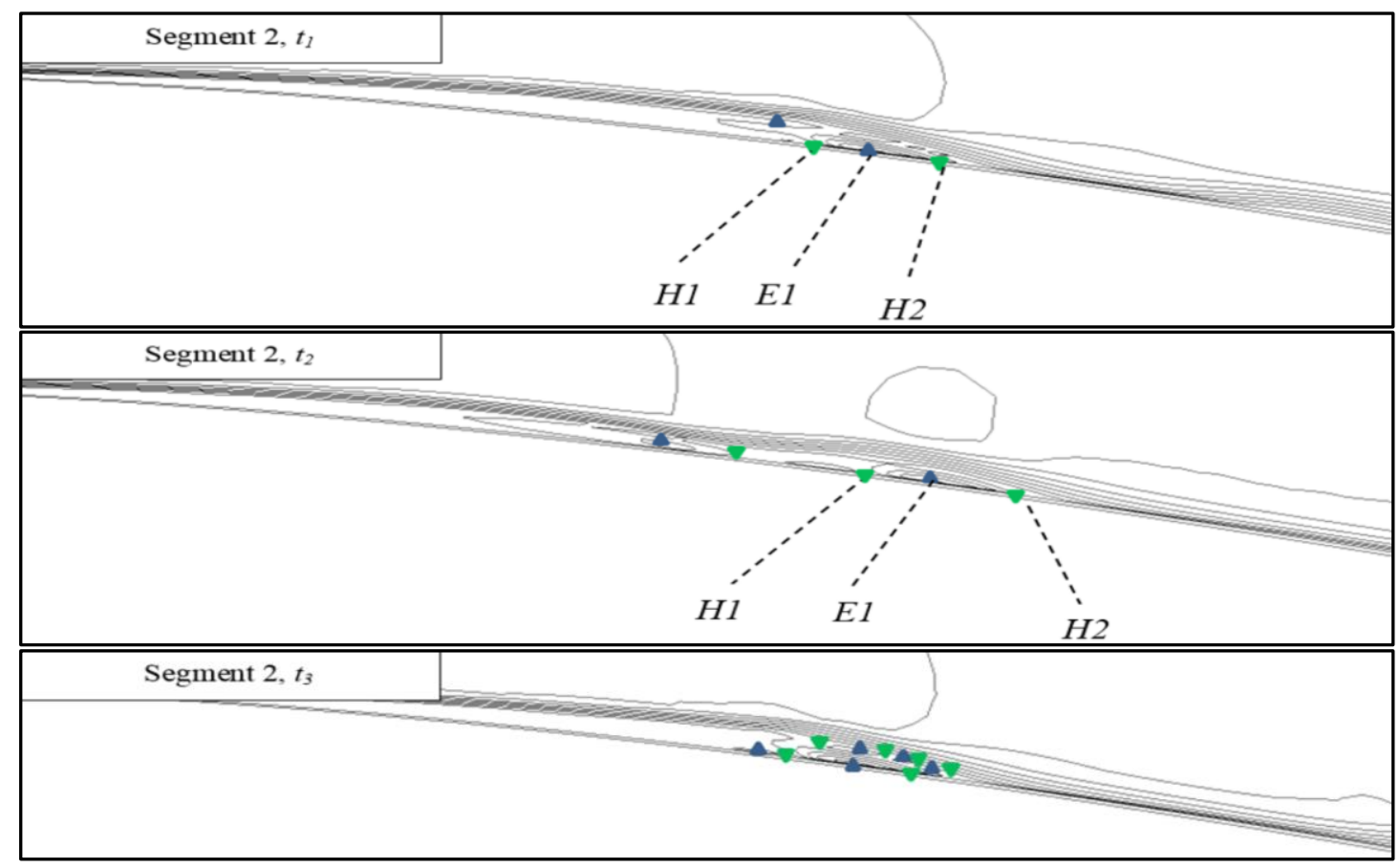

Fig. 21. Segmented flow topology (segment 2) around S3025 with $R e=60,000$ at $\alpha=4^{\circ}$ 


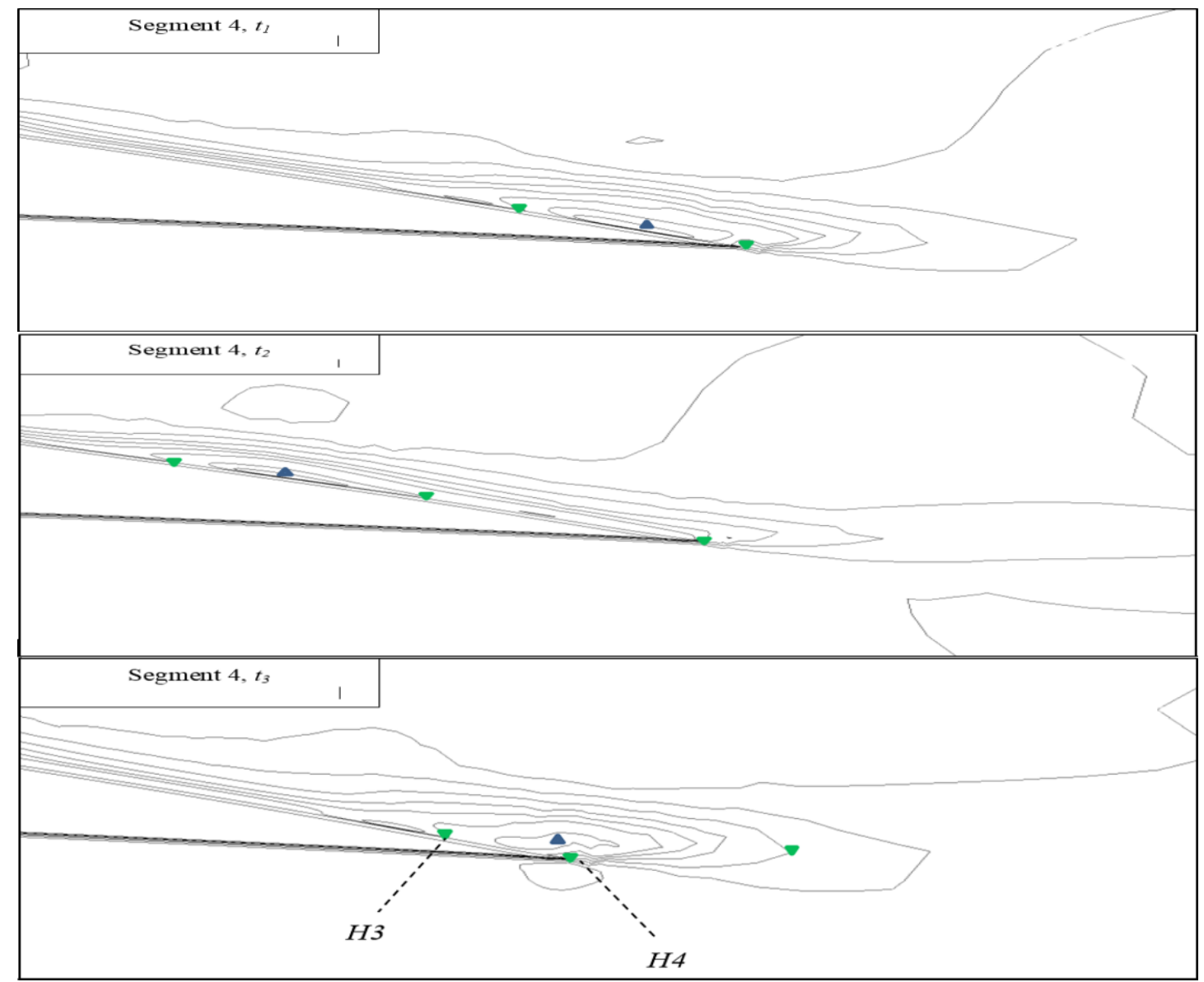

Fig. 22. Segmented flow topology (segment 4) around S3025 with $R e=60,000$ at $\alpha=4^{\circ}$

Table 10

Values of $c_{l}$ and $c_{d}$

\begin{tabular}{lll}
\hline Time & $\mathrm{Cl}_{1}$ & $\mathrm{Cd}_{\mathrm{d}}$ \\
\hline $\mathrm{t}_{1}$ & $8.1121 \times 10^{-1}$ & $1.1146 \times 10^{-2}$ \\
$\mathrm{t}_{2}$ & $8.3160 \times 10^{-1}$ & $1.4404 \times 10^{-2}$ \\
$\mathrm{t}_{3}$ & $7.5115 \times 10^{-1}$ & $2.2434 \times 10^{-2}$ \\
\hline
\end{tabular}

\subsection{Flow Topology Around Airfoil S3021}

The reverse saddle-node bifurcation and vortex shedding occur at $t_{2}$ and $t_{3}$, respectively. The number of singular fixed points as shown in Table 11 satisfy Eq. (1).

Table 11

Validation of topological fixed points in the flow over S3021 where Eq. (1) is satisfied when $n=1$

\begin{tabular}{lllll}
\hline Time & $\mathrm{E}$ & $\mathrm{E}^{\prime}$ & $\mathrm{H}$ & $\mathrm{H}^{\prime}$ \\
\hline $\mathrm{t}_{1}$ & 5 & 0 & 1 & 8 \\
$\mathrm{t}_{2}$ & 6 & 0 & 3 & 6 \\
$\mathrm{t}_{3}$ & 5 & 0 & 2 & 6 \\
\hline
\end{tabular}

There is no significant activity in segment 1 as shown in Figure 23. At $t_{2}$ in segment 2 as shown in Figure 24, it can be seen that points $\mathrm{E} 1, \mathrm{H} 1$ and $\mathrm{H} 2$ move towards the rear of the separation bubble. Consequently, $\mathrm{H} 1$ and $\mathrm{H} 2$ destroy each other in a collision that marks the occurrence of reverse 
saddle-node bifurcation. This results in the splitting of the separation bubble to produce a new fixed hyperbolic point.

The developing vortices towards the trailing edge from $t_{1}$ to $t_{3}$ is captured in segment 3 . At $t_{3}$ (Segment 4 as shown in Figure 25), three-way hyperbolic points, namely $\mathrm{H} 2$ and $\mathrm{H} 3$ collide each other as they move towards the airfoil's rear which then separate from the airfoil surface. The collision creates a new four-way hyperbolic point located right below the shed vortex.

The highest lift as shown in Table 12 is observed at $t_{2}$ where $c_{l}=6.9714 \times 10^{-1}$. At this time, the reattachment length of the separation bubble is the smallest and there is no occurrence of vortex shedding. However, the separation bubble at $t_{2}$ is relatively thicker than that at $t_{1}$, resulting a bump which slightly disturb the air flow and negatively affect the drag (i.e. increases the drag). The separation bubble then gets thinner at $t_{3}$ when the reverse saddle-node bifurcation takes place and splits the separation bubble to produce a new vortex. The smallest lift with $c_{l}=6.6406 \times 10^{-1}$ is found at $t_{1}$ where the reattachment length is the biggest.

Table 12

Values of $c_{/}$and $c_{d}$

\begin{tabular}{lll}
\hline Time & $\mathrm{Cl}_{1}$ & $\mathrm{C}_{d}$ \\
\hline $\mathrm{t}_{1}$ & $6.6406 \times 10^{-1}$ & $2.7324 \times 10^{-3}$ \\
$\mathrm{t}_{2}$ & $6.9714 \times 10^{-1}$ & $8.1822 \times 10^{-3}$ \\
$\mathrm{t}_{3}$ & $6.7221 \times 10^{-1}$ & $5.3508 \times 10^{-3}$ \\
\hline
\end{tabular}

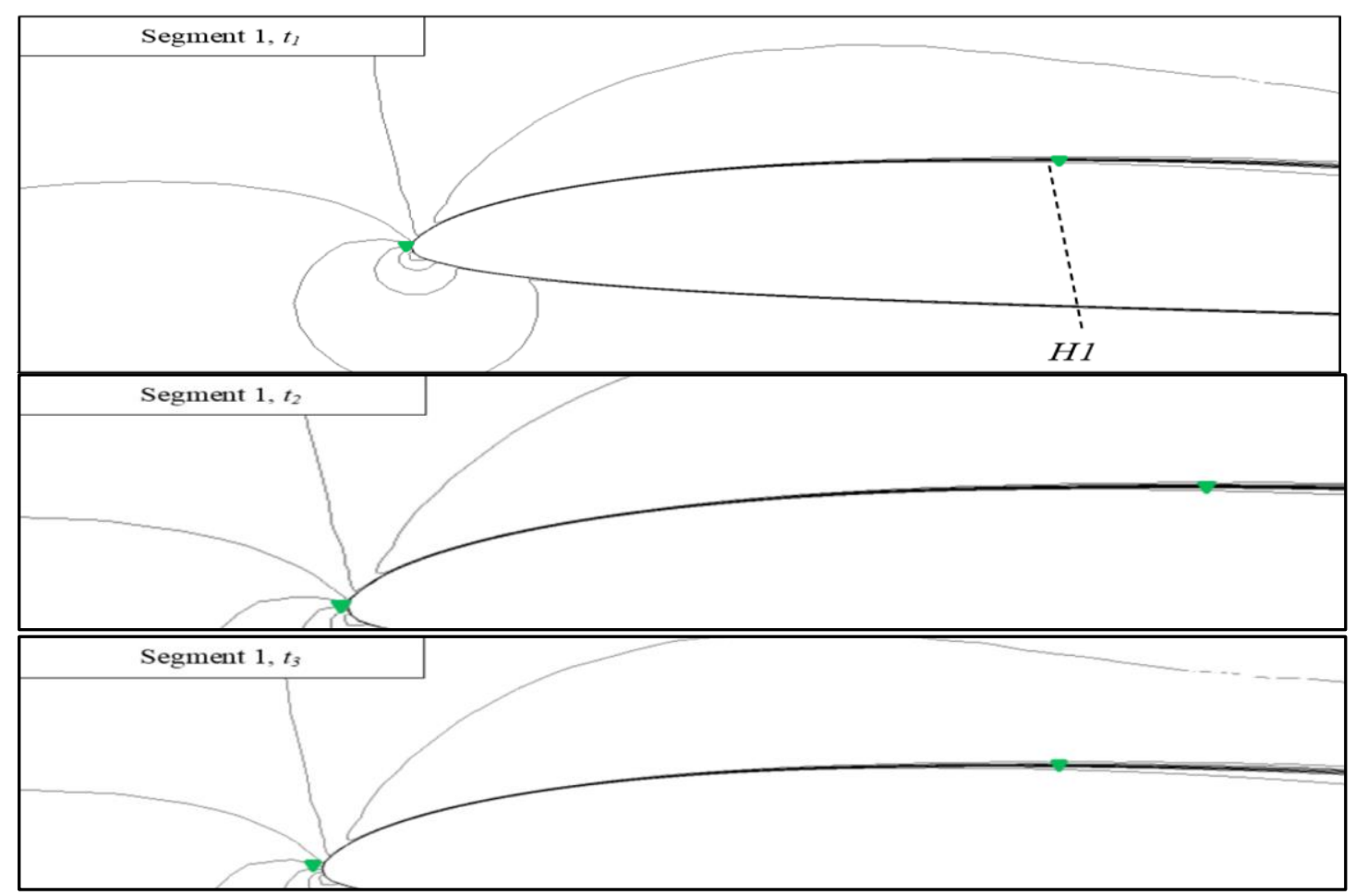

Fig. 23. Segmented flow topology (segment 1) around S3021 with $R e=60,000$ at $\alpha=4^{\circ}$ 


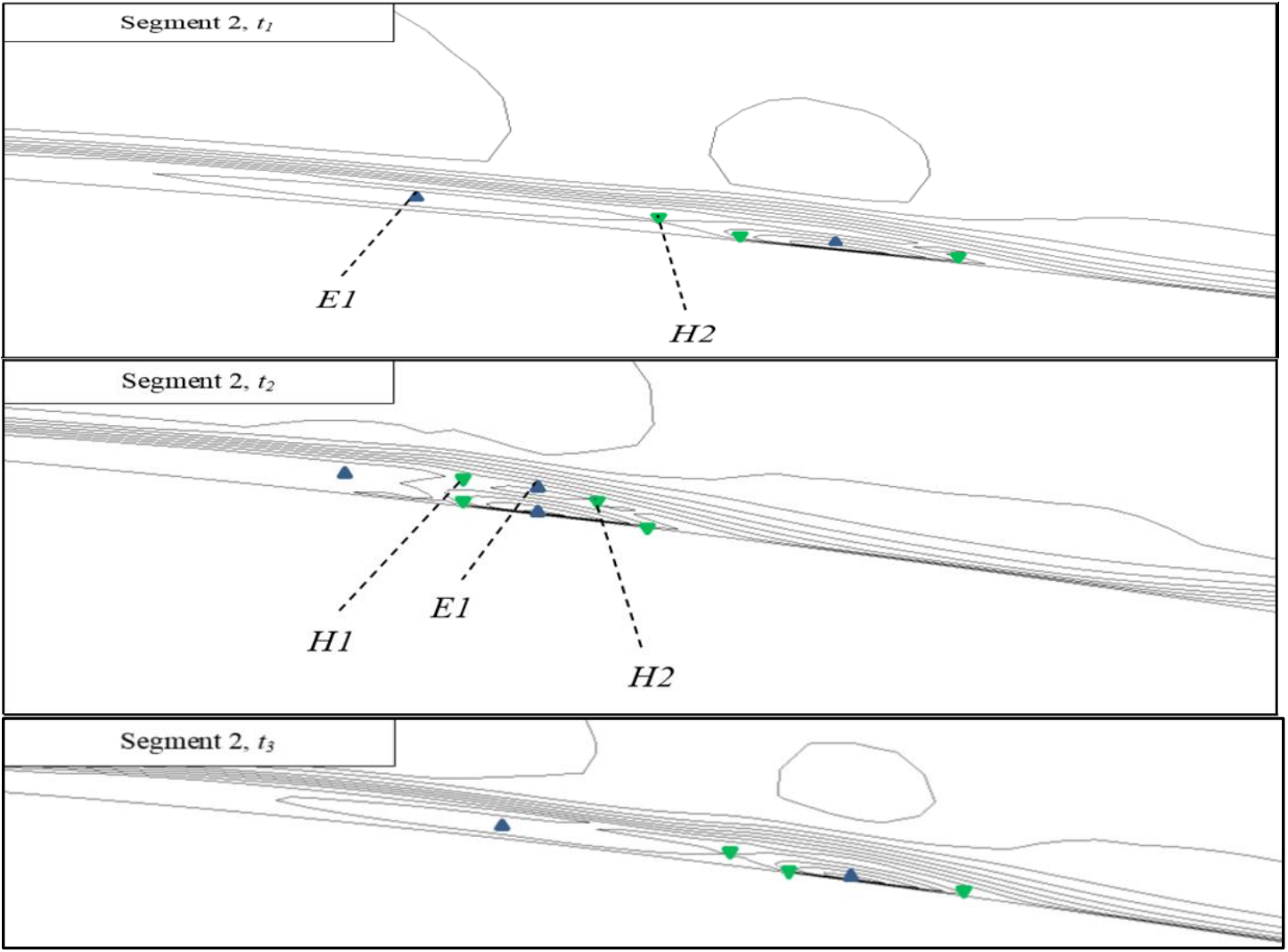

Fig. 24. Segmented flow topology (segment 2) around S3021 with $R e=60,000$ at $\alpha=4^{\circ}$

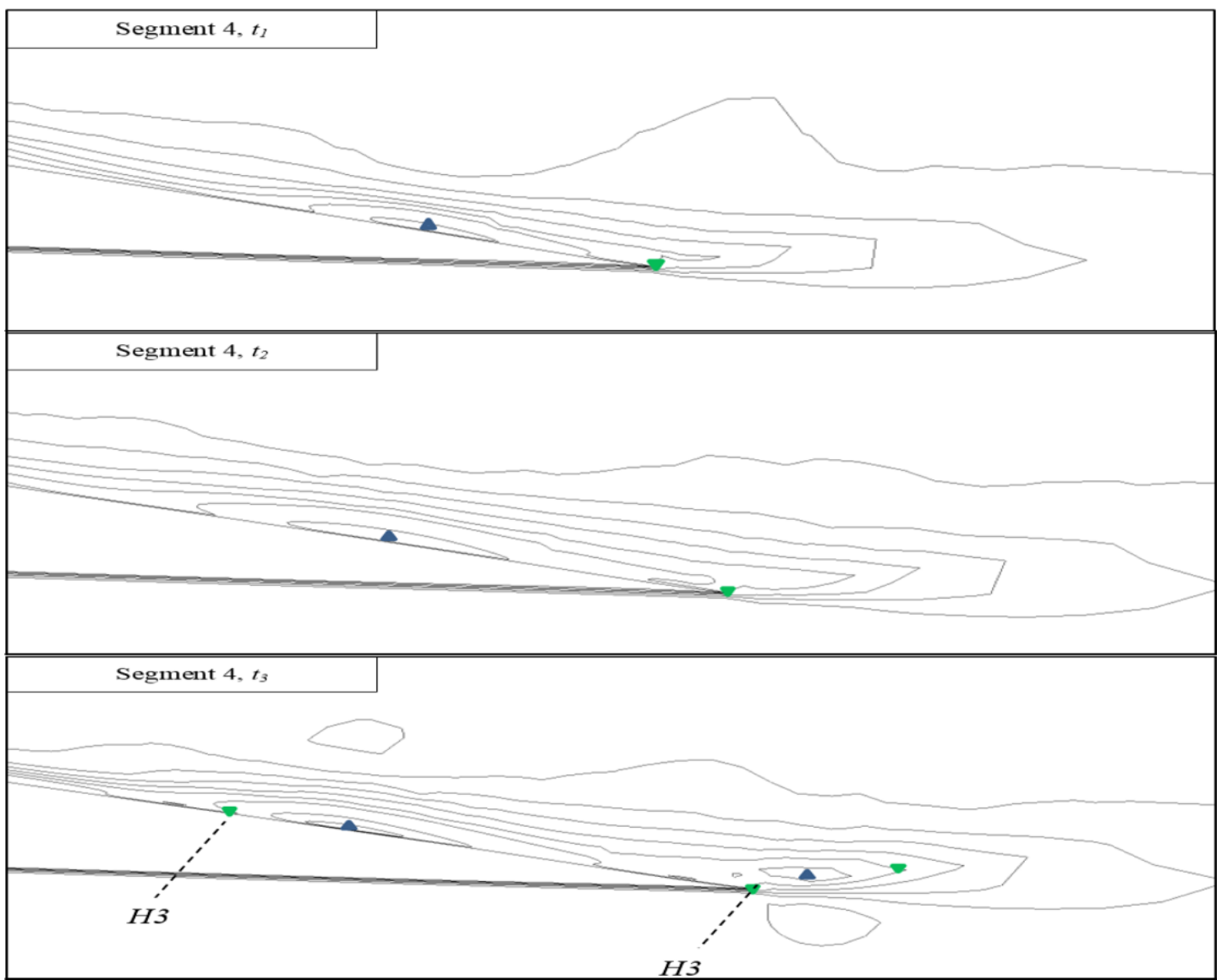

Fig. 25. Segmented flow topology (segment 4) around S3021 with $R e=60,000$ at $\alpha=4^{\circ}$ 


\section{Conclusions}

Six low Reynolds number airfoils were considered to investigate the reattachment point, separation bubble structure, and vortex shedding. Based on the simulation and analysis of the results, there are several findings which are useful in the application of micro aerial vehicle. Firstly, these airfoils resist to complete flow separation which would lead to stall. Regular airfoils tend to have complete flow separation when operate in low Reynolds number regime. It has been shown in this paper that the reattachment length is possibly reduced after its maximum which illustrates the effectiveness of the airfoils of interest.

The separation bubble formed on the surface of the airfoil disturbs the flow of air along the surface. When the air passes the bubble, the velocity of air decreases, thus causes the rise in pressure that would lead to potential boundary layer separation. The boundary layer is originally in tangential direction to the surface and is highly sensitive to any disturbance as the separation bubble. If a disturbance leads to instability, then the laminar flow would become turbulence which is a state unfavourable to any flying device. In the case of low Reynolds number airfoils as those considered in this study, the streamlines reattach to the airfoil surface while passing the separation bubble, thus prevent the transition to turbulent flow.

If a separation bubble is formed, it needs to contain as few vortices and to be as thin as possible in order to avoid complete flow separation. Thicker separation bubble which might be associated to more vortices it contains increases the drag.

Finally, the vortex shedding directly lowers the lift and increases the drag. Shedding of vortices is one of the unfavourable conditions in flying machines and cannot be totally eradicated. Nevertheless, giving the right technique, its effects can be minimized.

The main causes for the minimum and maximum values of lift and drag are summarized in Table 13 and Table 14, respectively.

Table 13

Main cause/s of minimum lift

\begin{tabular}{ll}
\hline Airfoils & Main cause/s \\
\hline E 387 & vortex shedding \\
E 374 & vortex shedding \\
E 392 & vortex shedding \\
S 3024 & vortex shedding \\
S 3025 & vortex shedding + thick separation bubble \\
S 3021 & big reattachment length \\
\hline
\end{tabular}

Table 14

Main cause/s of maximum drag

\begin{tabular}{ll}
\hline Airfoils & Main cause/s \\
\hline E 387 & high number of vortices in the separation bubble \\
E 374 & thick separation bubble \\
E 392 & secondary separation bubble \\
S 3024 & high number of vortices in the separation bubble \\
S 3025 & high number of vortices in the separation bubble \\
S 3021 & thick separation bubble \\
\hline
\end{tabular}

The determinations of singular fixed points throughout the study were successfully validated against Hunt relationship in Eq. (1). 


\section{Acknowledgement}

The author would like to thank Universiti Tun Hussein Onn Malaysia (UTHM) and Ministry of Higher Education of Malaysia (MoHE) for the research facilities. This research is supported by Research Fund E15501 under Research Management Centre, UTHM.

\section{References}

[1] Perry, A. E., and M. S. Chong. "Topology of flow patterns in vortex motions and turbulence." Applied Scientific Research 53, no. 3-4 (1994): 357-374. https://doi.org/10.1007/BF00849110

[2] Moffatt, H. Keith. "Some remarks on topological fluid mechanics." In An introduction to the geometry and topology of fluid flows, pp. 3-10. Springer, Dordrecht, 2001.

https://doi.org/10.1007/978-94-010-0446-6 1

[3] Lipinski, Doug, Blake Cardwell, and Kamran Mohseni. "A Lagrangian analysis of a two-dimensional airfoil with vortex shedding." Journal of Physics A: Mathematical and Theoretical 41, no. 34 (2008): 344011. https://doi.org/10.1088/1751-8113/41/34/344011

[4] Rubenstein, David, Wei Yin, and Mary D. Frame. Biofluid mechanics: an introduction to fluid mechanics, macrocirculation, and microcirculation. Academic Press, 2015.

https://doi.org/10.1016/B978-0-12-800944-4.00001-9

[5] Hadi, Muhammad Irfan, Mohd Nazri, and Aslam Abdullah. "Vortex formation in unsteady flow over NACA 4412 and NACA 4424 airfoils." ARPN J. Eng. Appl. Sci 15, no. 1 (2020): 27-33.

[6] Abdullah, Aslam, Amirul Aizad Roslan, and Zamri Omar. "Comparative study of turbulent incompressible flow past NACA airfoils." ARPN J. Eng. Appl. Sci 13, no. 21 (2018): 8527-8530.

[7] Abdullah, Aslam, M. N. S. M. Jafri, and Mohd Fadhli Zulkafli. "Numerical study of military airfoils design for compressible flow." ARPN J. Eng. Appl. Sci 12, no. 24 (2006): 1-5.

[8] Abdullah, Aslam, Muhammad Nasreen Yazi, Mohammad Fahmi Abdul Ghafir, Sofian Mohd, and Mohammad Zulafif Rahim. "Ground proximity effect on the flow over NACA 4412 multi-element airfoil in clean configuration." In IOP Conf. Series: Journal of Physics: Conf. Series, vol. 914, pp. 1-8. 2017. https://doi.org/10.1088/1742-6596/914/1/012005

[9] Okrepilov, Vladimir, Svetlana Kuzmina, and Sergey Kuznetsov. "Tools of quality economics: sustainable development of a 'smart city'under conditions of digital transformation of the economy." In IOP Conference Series: Materials Science and Engineering, vol. 497, no. 1, p. 012134. IOP Publishing, 2019. https://doi.org/10.1088/1757-899X/497/1/012134

[10] Rashidi, Saman, Masoud Hayatdavoodi, and Javad Abolfazli Esfahani. "Vortex shedding suppression and wake control: A review." Ocean Engineering 126 (2016): 57-80. https://doi.org/10.1016/i.oceaneng.2016.08.031

[11] Kurtulus, Dilek Funda. "Introduction to micro air vehicles: concepts, design and applications." feedback 3 (2011): 5.

[12] Hadi, M. I., M. Nazri, and Aslam Abdullah. "Study of vortex behavior in unsteady flow over NACA 0012 and NACA 0024 airfoils." ARPN J. Eng. Appl. Sci. 14, no. 22 (2019): 3840-3846.

[13] Tajuddin, Nurulhuda, Shabudin Mat, Mazuriah Said, and Shumaimi Mansor. "Flow characteristic of blunt-edged delta wing at high angle of attack." Journal of Advanced Research in Fluid Mechanics and Thermal Sciences 39, no. 1 (2017): 17-25.

[14] Hamizi, Ilya Bashiera, and Sher Afghan Khan. "Aerodynamics investigation of delta wing at low Reynold's number." CFD Letters 11, no. 2 (2019): 32-41.

[15] Hakim, Muhammad Syahmi Abdul, Norazila Othman, Mastura Ab Wahid, Shabudin Mat, Shuhaimi Mansor, Md Nizam Dahalan, and Wan Khairuddin Wan Ali. "The effects of Reynolds number on flow separation of Naca Aerofoil." Journal of Advanced Research in Fluid Mechanics and Thermal Sciences 47, no. 1 (2018): 56-68. 